Journal of Attention Disorders Vol. 3(2):85-89 (1999)

ISSN: $1087-0547$

doi:10.1177/108705479900300202

This is a peer reviewed pre-print version of the following article: The Multidimensional Anxiety Scale for Children (MASC): Confirmatory factor analysis in a pediatric ADHD sample, which has been published in final form at: http://www.sagepub.com/home.nav

http://jad.sagepub.com/

http://jad.sagepub.com/content/3/2/85.full.pdf+html

(C) Multi-Health Systems Inc., 1999

\title{
The Multidimensional Anxiety Scale for Children (MASC): Confirmatory factor analysis in a pediatric ADHD sample
}

\author{
J.S. March, C. Conners, G. Arnold, J. Epstein, J. Parker, S. Hinshaw, H. Abikoff, B. \\ Molina, K. Wells, J. Newcorn, S. Schuck, W.E. Pelham, B. Hoza
}

While considerable attention has been paid to discriminating attention-deficit/hyperactivity and anxiety disorders, there are as yet no published confirmatory factor analytic studies of any self-report anxiety scale in ADHD youth. The Multidimensional Anxiety Scale for Children (MASC) is a 39-item, 4-point Likert self-report scale that robustly represents the factor structure of anxiety in children aged 8 to 18 years. Using confirmatory factor analytic methods, the present paper reports a replication of the four-factor measurement model for the MASC in a large sample of ADHD youth aged 7 to 10 years. The fit indices proved to be comparable to those obtained in the MASC clinical and non-clinical (normative) samples. Clinically, therefore, this report strengthens confidence that the MASC is a valid measure of anxiety in diverse populations. With respect to research, it provides supporting evidence that results obtained using the MASC in the MTA and other research studies reflect valid estimates of anxiety in those samples.

Presumably because pathological anxiety is associated with significant suffering, disruption in normal psychosocial and academic development and family functioning, and increased utilization of medical services, "worry" is among the more common causes of referral to children's mental health care providers (Black, 1995; Simon, Ormel, VonKorff, \& Barlow, 1995). Nonetheless, the prevalence of childhood-onset fears in the population, the structure of anxiety symptoms in the general pediatric population, and the relative importance of specific anxiety dimensions within gender, ethnic, cultural, or neuropsychiatric disorder-based groupings has remained unclear, in part because of a lack of acceptable measurement tools (Costello \& Angold, 1995; Last, Perrin, Hersen, \& Kazdin, 1992).

We recently described the development and preliminary factor structure of the Multidimensional Anxiety Scale for Children (MASC), which rectifies problems found with older instruments (March \& Parker, in press; March, Parker, Sullivan, Stallings, \& Conners, 1997a). The MASC is a 39-item, 4-point, Likert self-report scale, which has undergone extensive psychometric evaluation (March, 1998). The MASC main and subfactors include the following: (1) physical symptoms (tense/restless and somatic/autonomic), (2) social anxiety (humiliation/rejection and public performance fears), (3) harm avoidance (anxious coping and perfectionism) and (4) separation anxiety. The MASC contains two other empirically-derived subscales: (1) a 10-item unifactorial short form (MASC-10) intended for use in epidemiological and treatment outcome studies, and (2) a 12-item anxiety disorder index with a high degree of diagnostic efficiency (March, 1998). The Internal reliability and test-retest reliability for the MASC total score and all the factors and subfactors are in the satisfactory to excellent range (March et al., 1997a; March, Sullivan, \& Parker, in press).

A series of confirmatory factor analyses have been conducted for the four-factor MASC across multiple normal and psychopathological groupings (March, 1998). In the initial study, the 
four-factor model for the 39-item MASC met the criteria standards for adequacy of fit (Bentler, 1988) in both school-based population and clinical psychiatric samples March, 1998).

Subsequently, separate multi-sample confirmatory factor analyses were conducted to test whether the four-factor MASC was equivalent for males and females and for two age-groups: 12 years old and under and 13 years old and over. Multiple goodness-of-fit indicators revealed that the four-factor model fit well for both age-groups and both genders. Using gender as the exemplar, the non-normed fit index (NNFI, Bentler \& Bonnett, 1980) was 0.913, the comparative fit index (CFI, Bentler, 1988) was 0.916, and the incremental fit index (IFI, Bolen, 1989) was 0.917. Similar analyses demonstrated that the MASC factor structure was identical in white and black youth (March, 1998). The overall conclusion to be drawn is that the MASC factor structure is identical across these diverse samples of children and adolescents.

Unlike the RCMAS, which differentiates children with DSM-III-R anxiety and attention-deficit disorders from normals but not from each other (Perrin \& Last, 1992), the MASC shows reasonably robust discriminant validity for both ADHD and depression (March, Parker, Sullivan, Stallings, \& Conners, 1997b). For example, in a series of analyses using discriminant function analysis, an empirically derived Anxiety Index was used to predict group membership in children and adolescents aged 8 to 18 years with anxiety disorders versus age- and gender-matched normal and ADHD comparison groups. With normals, the overall correct classification rate was an excellent 95 percent. Not surprisingly, discriminating anxiety from ADHD is a much more difficult problem psychometrically than discriminating between subjects with and without clinical symptoms (Perrin \& Last, 1992). Nonetheless, the MASC Anxiety Index performs in the satisfactory range. Specifically, in an age- and gender-matched sample, 140 children and adolescents that met DSM-IV criteria for an anxiety disorder other than OCD, or for Attention Deficit/Hyperactivity Disorder (ADHD) sensitivity for the MASC, the Anxiety Index was $75 \%$, the specificity was $67 \%$, the positive predictive power was $73 \%$, the negative predictive power was $69 \%$, the false positive rate was $33 \%$, the false negative rate was $25 \%$, kappa was 0.42 , and the overall correct classification rate was $71 \%$. While not quite as robust as the anxiety/normal comparison, the Anxiety Index thus shows a quite acceptable ability to discriminate between children with anxiety and Attention-Deficit/Hyperactivity Disorder.

A limitation of these studies is the lack of $a$ priori confirmation that the factor structure of the MASC is identical in anxious and ADHD youth. Surprisingly, despite considerable attention paid to the psychometric problems inherent is discriminating anxiety from ADHD (Conners, March, Erhardt, \& Butcher, 1995; March, 1998; March \& Albano, 1996), there are as yet no published confirmatory analytic studies of any self-report anxiety scales in ADHD youth. The six-site NIMH collaborative Multimodal Treatment Study of Children with ADHD (MTA) is the largest randomized clinical trial ever undertaken in children by the NIMH (Arnold et al., 1997). The MTA addresses a priori questions about the individual and combined effects of pharmacological and psychosocial (behavioral) treatment for children aged 7 to 10 years with ADHD. Among the instruments used in the MTA, the MASC was chosen as the sole self-report instrument for assessing anxiety (Hinshaw et al., 1997). The present paper, using confirmatory factor analytic methods and baseline pre-treatment data from the MTA sample, reports a replication of the four-factor measurement model for the MASC.

\section{Subjects}

The rationale and design of the MTA have been reported elsewhere (Arnold et al., 1997; Hinshaw et al., 1997). Briefly, 579 children aged 7 to 9 years and with DSM-IV ADHD (combined type) were selected by using a multiple-gate study entry procedure, after which they 
were randomly assigned to one of the following treatments: medication management, a multi-component psychosocial/ behavioral treatment, the combination of medication and psychosocial treatment, or community-control assessment-and-referral. The MTA sample is representative of the broad range of ADHD youth. Eighty-two percent are male; the mean age is 8.2 years; and 69\% are Caucasian, with the remainder predominately African/American and Hispanic/Latino. Approximately $20 \%$ are on welfare and $30 \%$ are from single-parent families. The current report includes pre-treatment baseline data from the entire MTA sample for which the MASC was available $(n=571)$.

\section{Statistical Methods}

Confirmatory factor analysis (CFA) using full maximum likelihood estimates was conducted using SPSS AMOS 3.61 (Arbuckle, 1996). The four MASC factors represent a moderately correlated subset of a unitary anxiety factor CFA (March, 1997; March, 1998), which argues against the need for statistical independence at the factor level in CFA. Hence, based on theoretical considerations, the four main MASC factors were allowed to covary in the final CFA model. Item error terms were allowed to covary within but not across the four MASC factors. Multiple goodness-of-fit indicators were calculated according to Arbuckle (1996). Because each index has different strengths and weaknesses in assessing the goodness-of-fit between a hypothetical model and the actual data, multiple indices are generally thought to be necessary to adequately evaluate model fit to the data (Arbuckle, 1996; Bentler, 1995)

\section{Results}

For the four-factor MASC model, the adjusted goodness of fit index (AGFI) was .900, the non-normed fit index (NNFI) was 0.910, the comparative fit index (CFI) was 0.918, the incremental fit index (IFI) was 0.920 and the RMSEA was .031. As suggested by Bentler (1995), values indicating that the model shows excellent fit of the model to the data are AGFI $>0.800$, NNFI $>.900$, CFI $>.900$, the IFI $>.900$ and RMSEA $<0.05$, indicating that the four-factor MASC model shows excellent fit to the data in the MTA sample. To allow evaluation of the relative importance of each MASC item loading on the four main MASC factors, Table 1 reports standardized regression (beta) weights for each item. Additionally, correlation coefficients for the four MASC factors in this model fell in the expected range: physical*harm avoidance = 0.375 , social $*$ separation $=0.832$, physical $*$ social $=0.772$, harm avoidance* separation $=0.645$, social $*$ harm avoidance $=0.540$, physical $*$ separation $=0.829$.

\section{Conclusion}

The overall conclusion gained from this study is that the MASC factor structure replicates satisfactorily in a sample of children with ADHD. Indeed, fit indices in this sample are only slightly less robust than those in clinical and non-clinical samples that are broadly representative of both clinical and normal populations of children and adolescents aged 8 to 18 years.

Clinically, therefore, this report strengthens confidence that the MASC is a valid measure of anxiety in diverse populations, including youth with ADHD. With respect to research, it provides supporting evidence that results obtained using the MASC

\begin{tabular}{llll}
\hline $\begin{array}{l}\text { MASC } \\
\text { Item }\end{array}$ & & Factor & Estimate \\
\hline $\mathrm{m} 01$ & $\longleftarrow$ & phys & 0.415 \\
$\mathrm{~m} 05$ & $\longleftarrow$ & phys & 0.447
\end{tabular}




\begin{tabular}{|c|c|c|c|}
\hline m08 & $<-$ & phys & 0.612 \\
\hline $\mathrm{m} 12$ & $<$ & phys & 0.559 \\
\hline $\mathrm{ml} 5$ & $<$ & phys & 0.402 \\
\hline $\mathrm{m} 18$ & $<$ & phys & 0.495 \\
\hline $\mathrm{m} 20$ & $<$ & phys & 0.616 \\
\hline $\mathrm{m} 24$ & $<$ & phys & 0.546 \\
\hline m27 & $<$ & phys & 0.471 \\
\hline m31 & $<$ & phys & 0.438 \\
\hline m35 & $<-$ & phys & 0.508 \\
\hline m38 & $<$ & phys & 0.472 \\
\hline $\mathrm{m} 03$ & $<$ & SOC & 0.500 \\
\hline $\mathrm{m} 10$ & $<$ & SOC & 0.635 \\
\hline $\mathrm{m} 14$ & $<-$ & SOC & 0.580 \\
\hline $\mathrm{m} 16$ & $<$ & SOC & 0.609 \\
\hline $\mathrm{m} 22$ & $<$ & SOC & 0.661 \\
\hline m29 & $<-$ & SOC & 0.523 \\
\hline m33 & $<$ & SOC & 0.522 \\
\hline m37 & $<-$ & SOC & 0.539 \\
\hline m39 & $<$ & SOC & 0.449 \\
\hline $\mathrm{m} 02$ & $<$ & HA & 0.343 \\
\hline m06 & $<-$ & HA & 0.456 \\
\hline m09 & $<-$ & HA & 0.345 \\
\hline $\mathrm{m} 13$ & $<-$ & HA & 0.602 \\
\hline m21 & $<-$ & HA & 0.367 \\
\hline m25 & $<-$ & HA & 0.529 \\
\hline m28 & $<-$ & HA & 0.302 \\
\hline m32 & $<-$ & HA & 0.583 \\
\hline m36 & $<-$ & HA & 0.501 \\
\hline $\mathrm{m} 04$ & $<-$ & sep & 0.519 \\
\hline $\mathrm{m} 07$ & $<-$ & sep & 0.477 \\
\hline $\mathrm{m} 11$ & $<-$ & sep & 0.387 \\
\hline $\mathrm{m} 17$ & $<-$ & sep & 0.329 \\
\hline m19 & $<-$ & sep & 0.385 \\
\hline m23 & $<-$ & sep & 0.308 \\
\hline m26 & $<-$ & sep & 0.355 \\
\hline m30 & $<$ & sep & 0.444 \\
\hline m34 & $<$ & sep & 0.526 \\
\hline
\end{tabular}

Table 1 Standardized regression weights

in the MTA and other research studies reflect true estimates of anxiety in those samples. In addition, replicating the factor structure across ADHD youth buttresses previous work demonstrating satisfactory discriminant validity for the MASC relative to normal and ADHD youth.

\section{Acknowledgments}

The MTA is a cooperative treatment study performed by six independent research teams in collaboration with the staff of the Division of Clinical and Treatment Research of the National Institute of Mental Health (NIMH), 
Rockville, Maryland and the Office of Special Education Programs (OSEP) of the U.S. Department of Education (DOE). The NIMH Principal Collaborators are Peter S. Jensen, MD, L. Eugene Arnold, MEd., MD, John E.

Richters, PhD, Joanne B. Severe, MS, Donald Vereen, MD, and Benedetto Vitiello, MD. Principal Investigators and Coinvestigators from the six sites are as follows: University of California at Berkeley/San Francisco (UOl MH50461): Stephen P. Hinshaw, PhD, Glen R. Elliott, MD, PhD; Duke University (UOl MH50447): C. Keith Conners, PhD, Karen C. Wells, PhD, John S. March, MD, MPH; University of California at Irvine/Los Angeles (UOl MH50440): James M. Swanson, PhD; Dennis P. Cantwell, MD; Timothy Wigal, PhD; Long Island Jewish Medical Center/Montreal Children's Hospital (UOl MH50453): Howard B. Abikoff, PhD, Lily Hechtman, MD; New York State Psychiatric Institute/Columbia University/Mount Sinai Medical Center (UOl MH50454): Laurence L. Greenhill, MD, Jeffrey H. Newcorn, MD; University of Pittsburgh (UOl MH50467): William E. Pelham, PhD, Betsy Hoza, PhD. Helena C. Kraemer, PhD (Stanford University) is statistical and design consultant. The OSEP/DOE Principal Collaborator is Ellen Schiller, PhD.

\section{References}

Arbuckle, J. (1996). AMOS. Chicago: SmallWaters, Inc.

Arnold, L.E., Abikoff, H.B., Cantwell, D.P., Conners, C.K., Elliott, G., Greenhill, L.L., Hechtman, L., Hinshaw, S.P., Hoza, B., Jensen, P.S., Kraemer, H.C., March, J.S., Newcorn, J.H., Pelham, W.E., Richters, J.E., Schiller, E., Severe, J.B., Swanson, J.M., Veeren, D., \& Wells, K.C. (1997). National Institute of Mental Health Collaborative Multimodal Treatment Study of Children with ADHD (the MTA). Design challenges and choices. Archives of General Psychiatry, 45 (9), 865-870.

Bentler, P. (1988). Comparative fit indexes in structural models. Psychological Bulletin, 107, 238-246.

Bentler, P. (1995). EQS Structural Equations Program Manual. Encino, CA: Multivariate Software, Inc.

Bentler, P., \& Bonnett, D. (1980). Significance test and goodness of fit in the analysis of covariance structures. Psychological Bulletin, 88, 588-606.

Black, B. (1995). Anxiety disorders in children and adolescents. Current Opinions in Pediatrics, 7 (4), 387-391.

Bolen, K. (1989). A new incremental fit index for general structural equation models. Sociological Methods and Research, 17, 303-316.

Conners, C., March, J., Erhardt, D., \& Butcher, T. (1995). Assessment of attention-deficit disorders. Journal of Psychoeducational Assessment, 28, 186-205.

Costello, E.J., \& Angold, A. (1995). Epidemiology. In J. March (Ed.), Anxiety Disorders in Children and Adolescents (pp. 109-124). New York: Guilford Press.

Hinshaw, S., March, J., Abikoff, H., Arnold, L., Cantwell, D., Conners, C., Elliott, G., Greenhill, L., Halperin, J., Hechtman, L., Hoza, B., Jensen, P., March, J., Newcorn, J., Pelham, W., Richters, J., Severe, J., Schiller, E., Swanson, J., Veeren, D., Wells, K., \& Wigal, T. (1997). Comprehensive assessment of childhood attention-deficit hyperactivity disorder in the context of a multisite, multimodal clinical trial. Journal of Attention Disorders, 1 (4), 217-234.

Last, C., Perrin, S., Hersen, M., \& Kazdin, A.E. (1992). DSM-IIIR anxiety disorders in children: Sociodemographic and clinical characteristics. Journal of the American Academy of Child and Adolescent Psychiatry, 31 (6), 1070-1076.

March, J. (1998). Manual for the Multidimensional Anxiety Scale for Children (MASC). Toronto:

Multi-Health Systems Inc.

March, J., \& Albano, A. (1996). Assessment of anxiety in children and adolescents. In L. Dickstein, M. Riba, \& M. Oldham (Eds.), Review of Psychiatry XV (Vol. XV, pp. 405-427). Washington: American Psychiatric Press.

March, J., \& Parker, J. (in press). The Multidimensional Anxiety Scale for Children (MASC). In M. Maruish (Ed.), The Use of Psychological Testing for Treatment Planning and Outcome Assessment (2nd ed.). Mahweh, NJ: Lawrence Erlbaum.

March, J., Parker, J., Sullivan, K., Stallings, P., \& Conners, C. (1997a). The Multidimensional Anxiety Scale for Children (MASC): Factor structure, reliability and validity. Journal of the American Academy of Child and Adolescent Psychiatry, 36(4), 554-565.

March, J., Sullivan, K., \& Parker, J. (in press). Test-retest reliability of the Multidimensional Anxiety Scale for Children (MASC). Journal of Anxiety Disorders. 
March, J.S., Parker, J.D., Sullivan, K., Stallings, P., \& Conners, C.K. (1997b). The Multidimensional Anxiety Scale for Children (MASC): Factor structure, reliability, and validity.

Journal of the American Academy of Child and Adolescent Psychiatry, 36(4) 554-565.

Perrin, S., \& Last, C.G. (1992). Do childhood anxiety measures measure anxiety? Journal of Abnormal Child Psychology, 20 (6), 567-578.

Simon, G., Ormel, J., VonKorff, M., \& Barlow, W. (1995). Health care costs associated with depressive and anxiety disorders in primary care. American Journal of Psychiatry, 152 (3), 352-357. 